\title{
BMJ Open Stroke care and case fatality in people with and without schizophrenia: a retrospective cohort study
}

\author{
Moira K Kapral (D) ,1,2,3 Paul Kurdyak (1) ,2,3,4 Leanne K Casaubon, ${ }^{5}$ Jiming Fang, ${ }^{2}$ \\ Joan Porter, ${ }^{2}$ Kathleen A Sheehan ${ }^{4}$
}

To cite: Kapral MK, Kurdyak P, Casaubon LK, et al. Stroke care and case fatality in people with and without schizophrenia: a retrospective cohort study. BMJ Open 2021;11:e044766. doi:10.1136/ bmjopen-2020-044766

- Prepublication history and supplemental material for this paper is available online. To view these files, please visit the journal online (http://dx.doi. org/10.1136/bmjopen-2020044766).

Received 14 September 2020 Accepted 23 May 2021

\section{Check for updates}

(c) Author(s) (or their employer(s)) 2021. Re-use permitted under CC BY-NC. No commercial re-use. See rights and permissions. Published by BMJ.

${ }^{1}$ Department of Medicine, Division of General Internal Medicine, University of Toronto, Toronto, Ontario, Canada ${ }^{2}$ ICES, Toronto, Ontario, Canada ${ }^{3}$ Institute of Health Policy, Management and Evaluation, University of Toronto, Toronto, Ontario, Canada

${ }^{4}$ Department of Psychiatry, University of Toronto, Toronto, Ontario, Canada

${ }^{5}$ Department of Medicine, Division of Neurology, University of Toronto, Toronto, Ontario, Canada

Correspondence to

Dr Moira K Kapral;

moira.kapral@uhn.ca

\section{ABSTRACT}

Background Schizophrenia is associated with an increased risk of death following stroke; however, the magnitude and underlying reasons for this are not well understood.

Objective To determine the association between schizophrenia and stroke case fatality, adjusting for baseline characteristics, stroke severity and processes of care.

Design Retrospective cohort study used linked clinical and administrative databases.

Setting All acute care institutions $(\mathrm{N}=152)$ in the province of Ontario, Canada.

Participants All patients ( $\mathrm{N}=52473$ ) hospitalised with stroke between 1 April 2002 and 31 March 2013 and included in the Ontario Stroke Registry. Those with schizophrenia $(n=612)$ were identified using validated algorithms.

Main outcomes and measures We compared acute stroke care in those with and without schizophrenia and used Cox proportional hazards models to examine the association between schizophrenia and mortality, adjusting for demographics, comorbidity, stroke severity and processes of care.

Results Compared with those without schizophrenia, people with schizophrenia were less likely to undergo thrombolysis $(10.1 \%$ vs $13.4 \%)$, carotid imaging $(66.3 \%$ vs $74.0 \%$ ), rehabilitation ( $36.6 \%$ vs $46.6 \%$ among those with disability at discharge) or be treated with antihypertensive, lipid-lowering or anticoagulant therapies. After adjustment for age and other factors, schizophrenia was associated with death from any cause at 1 year (adjusted HR (aHR) $1.33,95 \% \mathrm{Cl} 1.14$ to 1.54 ). This was mainly attributable to early deaths from stroke (aHR $1.47,95 \% \mathrm{Cl} 1.20$ to 1.80 , with survival curves separating in the first 30 days), and the survival disadvantage was particularly marked in those aged over 70 years (1-year mortality $46.9 \%$ vs $35.0 \%$ ). Conclusions Schizophrenia is associated with increased stroke case fatality, which is not fully explained by stroke severity, measurable comorbid conditions or processes of care. Future work should focus on understanding this mortality gap and on improving acute stroke and secondary preventive care in people with schizophrenia.

\section{INTRODUCTION}

Stroke is a leading cause of death and disability worldwide. ${ }^{1}$ Schizophrenia and other serious

\section{Strengths and limitations of this study}

Large, population-based sample with detailed clinical information on stroke characteristics and processes of care.

- Complete follow-up for outcome events through administrative data.

- Lack of information on some potential explanatory variables such as medication adherence and postdischarge care.

mental illnesses are associated with an increased risk of stroke, other cardiovascular diseases and cardiovascular mortality. ${ }^{2-4}$ This appears to be in part attributable to a higher prevalence of vascular risk factors including diabetes, obesity and smoking. ${ }^{5-8}$ Antipsychotic use, common in schizophrenia, is also associated with metabolic syndrome, cardiovascular disease and stroke incidence. ${ }^{9}$

The association between schizophrenia and stroke case fatality is less well understood, with some studies suggesting an increase ${ }^{31011}$ and others no difference ${ }^{12}$ or a decrease ${ }^{13}$ in poststroke mortality in those with schizophrenia. Prestroke antipsychotic use has been associated with an increased risk of severe stroke, which in turn could contribute to poststroke mortality in those with schizophrenia. ${ }^{14}$ Following myocardial infarction, the excess mortality observed in people with schizophrenia is in part explained by lower use of guideline-recommended interventions and medications. ${ }^{15-20}$ Previous research suggests that people with schizophrenia are also less likely to receive interventions for acute stroke care and secondary prevention, ${ }^{12}$ but it is not known whether such differences in care explain variations in stroke case fatality.

We used linked province-wide registry and administrative data to answer the research question of whether stroke presentation, processes of care and case fatality after stroke differed in people with and without 
schizophrenia. We hypothesised that schizophrenia would be associated with stroke case fatality and that differences in baseline characteristics and processes of care would account for this.

\section{METHODS}

\section{Setting, data sources and study sample}

Ontario is Canada's most populous province, with an estimated population of 13 million people at the time of this study. ${ }^{21}$ All residents have coverage for hospital and physician services.

The Ontario Stroke Registry collects detailed clinical information on a simple random sample of all people with stroke or transient attack seen in the emergency department or admitted to any acute care hospital in the province. ${ }^{22}$ This sampling minimises the biases associated with data collection from selected facilities and/or patient groups. ${ }^{23}$ Data collection is done by trained research personnel with the diagnosis of stroke confirmed by review of the chart and imaging results, and built-in data quality checks and programming ensure that there are no missing values. Validation by duplicate chart abstraction has shown excellent agreement for key variables. ${ }^{22}$

Our study cohort consisted of all adult (age $\geq 18$ years) patients hospitalised with acute stroke between 1 April 2002 and 31 March 2013 and included in the Ontario Stroke Registry. The registry provided detailed patientlevel information on stroke presentation and severity, comorbid conditions, processes of care and disability at discharge.

We linked registry data to population-based administrative databases using unique, encoded identifiers. To identify people with schizophrenia, we linked to the Canadian Institute for Health Information Discharge Abstract Database and the physician claims database. We defined schizophrenia in patients with any of the following: (1) a primary diagnosis of schizophrenia or schizoaffective disorder during a general hospital admission (using International Classification of Diseases, 10th revision (ICD-10) codes F20 or F25); (2) a primary diagnosis of schizophrenia from a psychiatric hospital bed (Diagnostic and Statistical Manual of Mental Disorders, Fourth Edition, 295.x); or (3) three outpatient visits with a diagnosis of schizophrenia (ICD-9-295) from outpatient physician billings within a 3-year period. Each of these criteria was applied from 1988 onward. This diagnostic algorithm has a sensitivity of $97 \%$ and a specificity of $65 \%$ for the diagnosis of schizophrenia. ${ }^{24}$

We used the 2006 Canada Census to provide information on median neighbourhood income and the Discharge Abstract Database to identify hospitalisations for recurrent stroke or transient ischaemic attack (TIA), using validated ICD-10 codes I60, I61, I63, I64, H34.0, H34.1 and G45 (excluding G45.4). ${ }^{25}$ We used the Ontario Registered Persons Database to identify deaths, with cause of death obtained from the provincial register that assigns cause of death based on death certificates, and with stroke deaths identified as those with ICD-10 codes I60-I69 as the primary cause of death.

\section{Outcomes}

The primary outcome was all-cause mortality within 1 year of stroke. Secondary outcomes were all-cause mortality at 30 days, death due to stroke at 1 year, disability at discharge (defined as a modified Rankin Scale (mRS) score of 3-5), and recurrent stroke hospitalisation within 30 days and 1 year of discharge from the index event. We also evaluated the following processes of care: arrival by ambulance, time from 'last seen normal' to hospital arrival, neuroimaging, dysphagia screening, delivery of care on a dedicated stroke unit, admission to intensive care unit (ICU), tracheostomy, placement of permanent feeding tube, a palliative approach to care and discharge to inpatient rehabilitation.

In the subgroup of patients with ischaemic stroke, we also evaluated use of carotid imaging, thrombolysis, door-to-needle time in those receiving thrombolysis and prescription of antithrombotic, and antihypertensive and lipid-lowering therapy at discharge. Among those who did not receive thrombolysis, we explored reasons why it was not given, categorised as arrival too late, contraindications, symptom severity, delays in decision-making, other physician decision or no reason documented. We did not evaluate use of endovascular thrombectomy, which was not in widespread use during the study time frame.

\section{Analysis}

We compared baseline characteristics and processes of care for people with stroke with and without schizophrenia, using standardised differences of the mean, which, unlike traditional hypothesis testing with $p$ values, are not sensitive to large sample sizes. ${ }^{26}$ We used a Cox proportional hazard model to estimate the effect of schizophrenia on the hazard of death. We then sequentially introduced covariates into the model as follows: (1) demographics (age and sex); (2) socioeconomic factors (neighbourhood income and rural residence); (3) clinical presentation (stroke type and severity); (4) comorbid conditions (smoking, diabetes, hyperlipidaemia, hypertension and prior stroke); (5) processes of care (brain imaging and stroke unit care); and (6) life-sustaining interventions (ICU admission, tracheostomy and permanent feeding tube). We repeated these models in the subgroup with ischaemic stroke, with the addition of the following covariates: (1) thrombolysis, (2) lipid-lowering therapy, (3) antihypertensive medications and (4) antithrombotic therapy. We then repeated these analyses for the outcome of death due to stroke, with cumulative incidence functions used to estimate the incidence of death due to stroke over time in people with and without schizophrenia, with death from other causes treated as a competing risk. In preliminary analyses, the proportional hazards assumption was violated for the allcause mortality models in the ischaemic stroke subcohort and weakly violated the assumption in the main cohort. 
We addressed this by estimating time-varying HRs using restricted cubic splines and modelling time-covariate interactions. ${ }^{27}$ This allowed for an investigation of the shape of a possible covariate-time dependence without having to specify a specific functional form.

ICES (formerly known as the Institute for Clinical Evaluative Sciences) is an independent, non-profit research institute whose legal status under Ontario's health information privacy law allows it to collect and analyse healthcare and demographic data, without consent, for health system evaluation and improvement. Datasets used in this project were linked using unique encoded identifiers and analysed at ICES. The lead author affirms that the manuscript is an honest, accurate and transparent account of the study being reported.

\section{RESULTS}

We studied 52473 patients hospitalised with acute stroke, of whom $612(1.2 \%)$ had schizophrenia. Compared with those without schizophrenia, people with schizophrenia were younger at the time of stroke (median age 66 vs 74 years), less likely to be independent prior to stroke $(44.9 \%$ vs $66.7 \%)$ and more likely to reside in a long-term care facility $(19.3 \%$ vs $5.1 \%)$ or to live in a low-income neighbourhood (39.2\% vs $22.9 \%$ ) (table 1$)$. Those with schizophrenia were also less likely to have a documented prestroke history of hypertension $(58.3 \%$ vs $63.7 \%$ ), hyperlipidaemia ( $30.2 \%$ vs $35.0 \%)$, atrial fibrillation $(8.8 \%$ vs $16.8 \%)$, coronary artery disease $(17.3 \%$ vs $21.6 \%$ ) or cancer $(4.7 \%$ vs $7.8 \%$ ), but more likely to have diabetes (31.0\% vs $23.7 \%)$, cognitive impairment ( $17.6 \%$ vs $8.7 \%)$ or to smoke cigarettes (28.3\% vs $16.5 \%)$ (standardised difference of the mean (std. diff.) $>0.10$ for all comparisons, table 1). Stroke type was similar in those with and without schizophrenia, but those with schizophrenia were less likely to present with mild stroke (54.7\% vs $60.9 \%$ ).

People with schizophrenia were more likely to arrive by ambulance $(79.9 \%$ vs $72.2 \%)$ but had a longer median time from symptom onset to hospital arrival (7.7 vs 5.8 hours). Those with schizophrenia were also more likely to be screened for dysphagia ( $59.0 \%$ vs $54.0 \%)$, but there were no significant differences in the use of stroke unit care, ICU admission or palliative care (table 2).

\begin{tabular}{|c|c|c|c|}
\hline & $\begin{array}{l}\text { Schizophrenia } \\
n=612\end{array}$ & $\begin{array}{l}\text { No schizophrenia } \\
n=51861\end{array}$ & Std. diff. \\
\hline Age (years), median (IQR) & $66(56-77)$ & $74(62-82)$ & 0.45 \\
\hline Female, n (\%) & $323(52.8)$ & $25552(49.3)$ & 0.07 \\
\hline Independent prior to admission, $\mathrm{n}(\%)$ & $275(44.9)$ & $34604(66.7)$ & 0.45 \\
\hline Long-term care, n (\%) & $118(19.3)$ & $2632(5.1)$ & 0.45 \\
\hline Lowest neighbourhood income quintile, n (\%) & $240(39.2)$ & $11860(22.9)$ & 0.36 \\
\hline Rural residence, n (\%) & $45(7.4)$ & $6599(12.7)$ & 0.18 \\
\hline Hypertension, n (\%) & $357(58.3)$ & $33051(63.7)$ & 0.11 \\
\hline Hyperlipidaemia, n (\%) & $185(30.2)$ & $18129(35.0)$ & 0.10 \\
\hline Diabetes, n (\%) & $190(31.0)$ & $12304(23.7)$ & 0.16 \\
\hline Atrial fibrillation, $\mathrm{n}(\%)$ & $54(8.8)$ & $8714(16.8)$ & 0.24 \\
\hline Coronary artery disease, $\mathrm{n}(\%)$ & $106(17.3)$ & $11211(21.6)$ & 0.11 \\
\hline Prior stroke, n (\%) & $126(20.6)$ & $8992(17.3)$ & 0.08 \\
\hline Cancer, n (\%) & $29(4.7)$ & $4035(7.8)$ & 0.13 \\
\hline Dementia/cognitive impairment, $\mathrm{n}(\%)$ & $108(17.6)$ & $4502(8.7)$ & 0.27 \\
\hline Current smoking, n (\%) & $173(28.3)$ & $8563(16.5)$ & 0.28 \\
\hline \multicolumn{4}{|l|}{ Stroke type, n (\%) } \\
\hline Ischaemic & $496(81.0)$ & $40734(78.5)$ & 0.06 \\
\hline Haemorrhagic & $116(19.0)$ & $11127(21.5)$ & 0.06 \\
\hline \multicolumn{4}{|l|}{ Stroke severity, $\mathrm{n}(\%)$} \\
\hline Mild (CNS>8) & $335(54.7)$ & $31605(60.9)$ & 0.13 \\
\hline Moderate (CNS 4-8) & $128(20.9)$ & $8746(16.9)$ & 0.10 \\
\hline Severe $(\mathrm{CSN}<4)$ & $149(24.3)$ & $11510(22.2)$ & 0.05 \\
\hline
\end{tabular}

CNS: lower scores indicate more severe strokes.

Std. diff: values of $>0.10$ are considered to represent a meaningful difference.

CNS, Canadian Neurological Scale; std. diff., standardised difference of the mean. 
Table 2 Presentation and processes of care in people with acute stroke with and without schizophrenia

\begin{tabular}{llll}
\hline & $\begin{array}{l}\text { Schizophrenia } \\
\mathbf{n = 6 1 2}\end{array}$ & $\begin{array}{l}\text { No schizophrenia } \\
\mathbf{n = 5 1 8 6 1}\end{array}$ & Std. diff. \\
\hline Arrival by ambulance, $\mathrm{n}(\%)$ & $489(79.9)$ & $37424(72.2)$ & 0.18 \\
\hline Time from symptom onset to ED arrival (hours), median (IQR) & $7.7(1.8-22.2)$ & $5.8(1.5-20.0)$ & 0.11 \\
\hline Dysphagia screening, $\mathrm{n}(\%)$ & $361(59.0)$ & $28022(54.0)$ & 0.10 \\
\hline Stroke unit care, $\mathrm{n}$ (\%) & $281(45.9)$ & $23717(45.7)$ & 0.004 \\
\hline Intensive care unit admission, $\mathrm{n}$ (\%) & $126(20.6)$ & $11499(22.2)$ & 0.04 \\
\hline Palliative approach to care, $\mathrm{n}$ (\%) & $102(16.7)$ & $7398(14.3)$ & 0.07 \\
\hline Subgroup with ischaemic stroke, $\mathrm{N}$ & 496 & 40734 & 0.17 \\
\hline Carotid imaging - $\mathrm{n}$ (\%) & $329(66.3)$ & $30157(74.0)$ & 0.10 \\
\hline Thrombolysis given -n (\%) & $50(10.1)$ & $5477(13.4)$ & 0.01 \\
\hline Reason thrombolysis not given - \% & & & 0.02 \\
\hline Arrival too late & 51.6 & 52.1 & 0.17 \\
\hline Contraindication & 10.5 & 10.0 & 0.05 \\
\hline Symptoms too mild & 21.3 & 28.5 & 0.08 \\
\hline Symptoms too severe & 5.4 & 4.4 & 0.05 \\
\hline Other physician decision & 11.0 & 8.7 & 0.07 \\
\hline Delayed decision & 2.2 & 3.1 & \\
\hline No reason documented & 10.3 & 8.4 & 0.18 \\
\hline Subgroup with ischaemic stroke alive at discharge, $\mathrm{N}$ & 433 & 36331 & 0.12 \\
\hline Antihypertensive therapy prescribed, $\mathrm{n}$ (\%) & $285(65.8)$ & 26966 (74.2) & 0.05 \\
\hline Lipid-lowering therapy prescribed, $\mathrm{n}$ (\%) & $270(62.4)$ & $24690(68.0)$ & 0.25 \\
\hline Antiplatelet therapy, $\mathrm{n}$ (\%) & $344(79.4)$ & $28119(77.4)$ & $6430 / 8971(71.7)$ \\
\hline Anticoagulation (in subgroup with atrial fibrillation), $\mathrm{n} / \mathrm{N}$ (\%) & $40 / 67(59.7)$ & & \\
\hline
\end{tabular}

Std. diff.: values of $>0.10$ are considered to represent a meaningful difference.

$\mathrm{ED}$, emergency department; std. diff., standardised difference of the mean.

In the subgroup with ischaemic stroke, people with schizophrenia were less likely to undergo thrombolysis ( $10.1 \%$ vs $13.4 \%)$, carotid imaging $(66.3 \%$ vs $74.0 \%)$, antihypertensive therapy $(65.8 \%$ vs $74.2 \%)$, lipidlowering therapy $(62.4 \%$ vs $68.0 \%)$ and anticoagulation for atrial fibrillation (59.7\% vs $71.7 \%$ ) (std. diff. $\geq 0.10$ for all comparisons, table 2). The reasons for not using thrombolysis were similar between groups.

We found no differences in length of stay or death or recurrent stroke/TIA hospitalisation in those with and without schizophrenia (table 3). However, people with schizophrenia were more likely to be disabled at discharge (mRS score of $3-5,54.3 \%$ vs $46.9 \%$ ) yet less likely to be discharged to inpatient rehabilitation facilities $(36.6 \%$ vs $46.6 \%$ in the disabled subgroup) (table 3 ).

Crude all-cause mortality was similar in those with and without schizophrenia at 30 days $(19.3 \%$ vs $16.6 \%)$ and 1 year $(28.1 \%$ vs $26.8 \%$ ) (table 3 ). However, after adjustment for age, sex, stroke severity, stroke type, area of residence, comorbid conditions and processes of care, schizophrenia was associated with an increased 1-year hazard of both all-cause mortality (adjusted HR (aHR) $1.33,95 \%$ CI 1.14 to 1.54 , c-statistic 0.78 ) and mortality due to stroke (aHR 1.47, 95\% CI 1.20 to 1.80 , c-statistic
0.82), with survival curves separating in the first month after the index stroke (table 4, figure 1 and online supplemental figure, the latter confirming time-varying HRs revealed by restricted cubic spline modelling; fully adjusted models are shown in online supplemental table). There was an interaction between age and schizophrenia, with the hazard of death associated with schizophrenia mainly seen in those aged 70 years and older (figure 2). In the subgroup aged over 70 years, people with schizophrenia had higher all-cause mortality at 30 days $(31.1 \%$ vs $20.9 \%$; std. diff. 0.24$)$ and 1 year $(46.9 \%$ vs $35.0 \%$, std. diff. 0.24 ) with the majority of deaths due to stroke rather than other causes (table 3 ).

\section{DISCUSSION}

In this population-based cohort study of people hospitalised with acute stroke, we found that while many processes of acute stroke care were similar between groups, schizophrenia was associated with delays in presentation and lower use of thrombolysis, vascular imaging, rehabilitation and medications for secondary prevention. Schizophrenia was also associated with a $33 \%$ increase in the hazard of 1-year poststroke mortality, even after adjustment for age, 
Table 3 Outcomes after acute stroke in people with and without schizophrenia

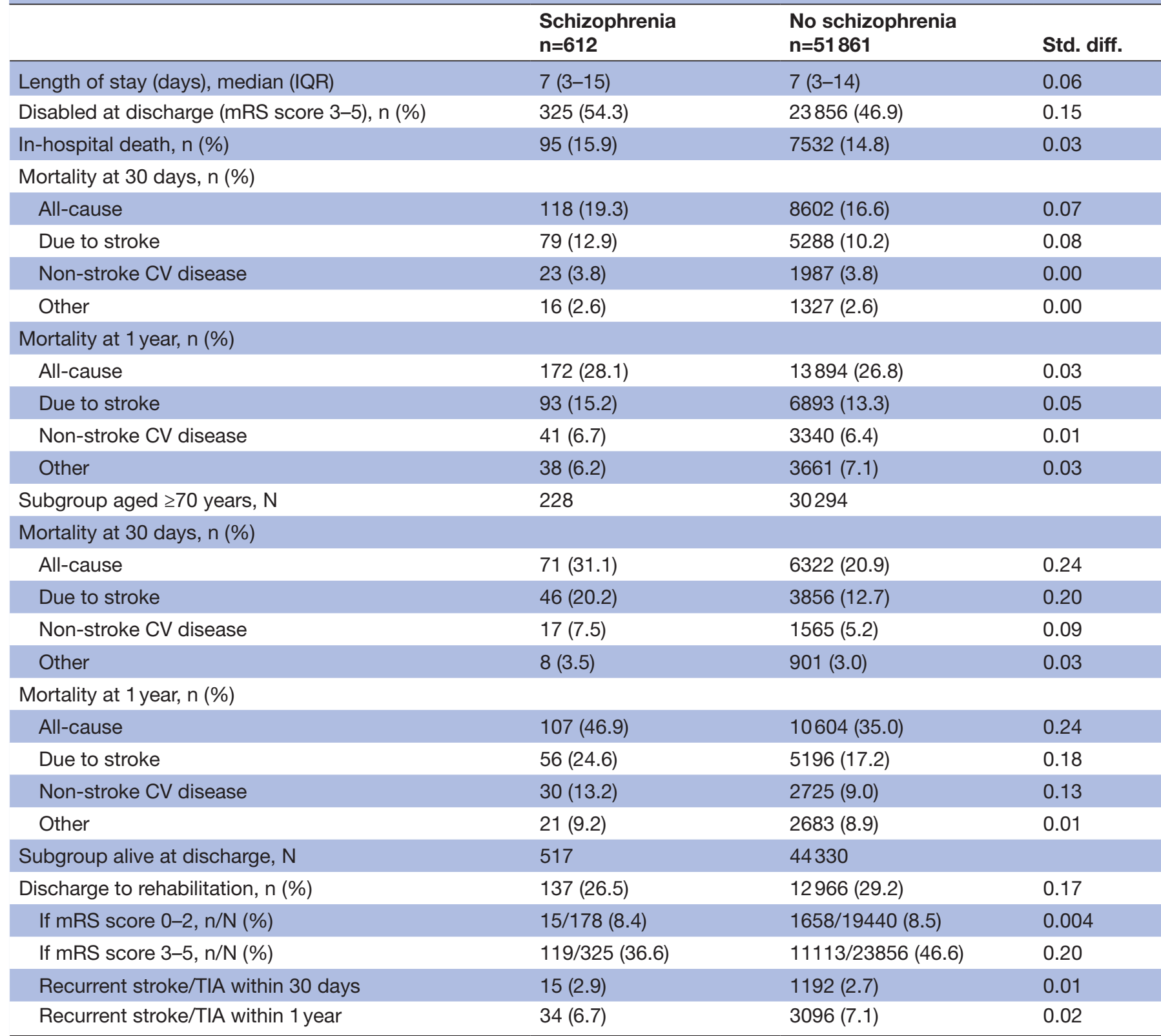

mRS: higher scores indicate more disability.

Std. diff.: values of $>0.10$ are considered to represent a meaningful difference.

mRS, modified Rankin Scale; std. diff., standardised difference of the mean; TIA, transient ischaemic attack.

sex, stroke type, stroke severity, comorbid conditions and processes of care, and this appeared to be mainly attributable to early deaths due to stroke in older patients.

Our findings of a younger age at stroke presentation and baseline differences in the prevalence of vascular risk factors in those with and without schizophrenia are consistent with previous studies of cardiovascular disease and risk factors in people with severe mental illness. ${ }^{5}{ }^{51728} 29$ Schizophrenia is associated with an increased prevalence of smoking, diabetes, obesity and hyperlipidaemia, as well as use of antipsychotic medications that increase the risk of metabolic syndrome. ${ }^{30}{ }^{31}$ Screening and management of these conditions have been promoted for the primary prevention of cardiovascular disease in people with schizophrenia, especially those on second-generation antipsychotic agents; however, screening rates remain suboptimal in many populations, ${ }^{31-34}$ as do efforts to manage these risk factors among individuals with schizophrenia. ${ }^{35}$ We cannot determine whether the lower prevalence of hypertension, hyperlipidaemia, atrial fibrillation and cardiovascular disease among people with schizophrenia in our cohort is due to a younger age at presentation or under-recognition of these conditions due to a lack of screening and preventive care.

It warrants mention that the prevalence of schizophrenia in our stroke cohort $(1.2 \%)$ was similar to that 
Table 4 Effect of sequential risk adjustment on the hazard of 1-year stroke case fatality associated with schizophrenia

\begin{tabular}{|c|c|c|c|}
\hline Adjustment & $\begin{array}{l}\text { All-cause mortality } \\
\text { HR }(95 \% \mathrm{Cl})\end{array}$ & $\begin{array}{l}\text { Death due to stroke } \\
\mathrm{HR}(95 \% \mathrm{Cl})\end{array}$ & $\begin{array}{l}\text { Non-stroke death } \\
\text { HR }(95 \% \mathrm{Cl})\end{array}$ \\
\hline - & $\begin{array}{l}1.08 \\
(0.93 \text { to } 1.25)\end{array}$ & $\begin{array}{l}1.16 \\
(0.94 \text { to } 1.42)\end{array}$ & $\begin{array}{l}0.98 \\
(0.78 \text { to } 1.22)\end{array}$ \\
\hline Age and sex & $\begin{array}{l}1.39 \\
(1.19 \text { to } 1.61)\end{array}$ & $\begin{array}{l}1.46 \\
(1.19 \text { to } 1.79)\end{array}$ & $\begin{array}{l}1.31 \\
(1.05 \text { to } 1.63)\end{array}$ \\
\hline Age and sex+income quintile, rural residence & $\begin{array}{l}1.38 \\
(1.19 \text { to } 1.60)\end{array}$ & $\begin{array}{l}1.46 \\
(1.19 \text { to } 1.80)\end{array}$ & $\begin{array}{l}1.28 \\
(1.03 \text { to } 1.60)\end{array}$ \\
\hline $\begin{array}{l}\text { Age and sex+income quintile and rural } \\
\text { residence+stroketype and stroke severity }\end{array}$ & $\begin{array}{l}1.31 \\
(1.13 \text { to } 1.52)\end{array}$ & $\begin{array}{l}1.40 \\
(1.14 \text { to } 1.72)\end{array}$ & $\begin{array}{l}1.21 \\
(0.97 \text { to } 1.52)\end{array}$ \\
\hline $\begin{array}{l}\text { Age and sex+income quintile and rural } \\
\text { residence+stroketype and stroke severity+smoking, } \\
\text { diabetes, hyperlipidaemia, hypertension, prior stroke }\end{array}$ & $\begin{array}{l}1.27 \\
(1.10 \text { to } 1.48)\end{array}$ & $\begin{array}{l}1.37 \\
(1.12 \text { to } 1.68)\end{array}$ & $\begin{array}{l}1.17 \\
(0.94 \text { to } 1.46)\end{array}$ \\
\hline $\begin{array}{l}\text { Age and sex+income quintile and rural } \\
\text { residence+stroketype and stroke severity+smoking, } \\
\text { diabetes, hyperlipidaemia, hypertension, prior } \\
\text { stroke+brain imaging within } 1 \text { hour of arrival, care } \\
\text { on stroke unit+intensive care unit admission, } \\
\text { tracheostomy, feeding tube }\end{array}$ & $\begin{array}{l}1.33 \\
(1.14 \text { to } 1.54)\end{array}$ & $\begin{array}{l}1.47 \\
(1.20 \text { to } 1.80)\end{array}$ & $\begin{array}{l}1.19 \\
(0.95 \text { to } 1.48)\end{array}$ \\
\hline
\end{tabular}

HR ratio for schizophrenia ( $n=612)$ vs no schizophrenia $(n=51861)$. Hazard of death due to stroke accounts for the competing risk of death from other causes.

in the general population, despite the increased risk of stroke associated with schizophrenia. ${ }^{37}$ Our finding that people with schizophrenia were less likely than those without to present with minor strokes suggests that there may be differences in care-seeking behaviour or challenges in making a diagnosis of stroke in people with less obvious stroke symptoms and concomitant schizophrenia, and that this group with minor strokes may be under-represented in our cohort. If true, this would represent a missed opportunity for care in people with schizophrenia and stroke, as minor strokes can be associated with disability, and secondary preventive care can prevent more major disabling strokes in the future. ${ }^{38} 39$

Our findings of lower use of thrombolysis, rehabilitation, carotid imaging and medications for secondary stroke prevention are consistent with previous studies where schizophrenia has been associated with lower use of various interventions after stroke $\mathrm{e}^{1140-42}$ and myocardial infarction. ${ }^{151619}$ A better understanding of the reasons behind these differences in care will be important to ensuring that people with schizophrenia have equal opportunities to receive appropriate treatment for cardiovascular disease.

We found that schizophrenia was associated with a striking 33\% increase in the adjusted hazard of all-cause mortality at 1 year and a $47 \%$ increase in the hazard of stroke mortality, with survival curves separating in the first month after stroke. Those with schizophrenia had greater stroke severity, the most important driver of early case fatality, compared with those without schizophrenia; however, the mortality difference persisted after adjustment for stroke severity. A similar association between schizophrenia and case fatality after myocardial infarction appears to be in part explained by differences in revascularisation and other processes of care $\mathrm{e}^{15-17192043-45}$; however, the observed association between schizophrenia and stroke case fatality in our study persisted after adjustment for processes of care, comorbid conditions and area of residence. Of note, the survival disadvantage associated with schizophrenia was primarily seen in the older age groups, in contrast to a study from Hong Kong which found that the association between schizophrenia and stroke case fatality was greater in those aged under 65 years. ${ }^{10}$ Further work is needed to understand the reasons for increased mortality in different age groups and to identify potential interventions to address this.

Some limitations of our study warrant emphasis. We did not have information on the severity or duration of schizophrenia, which would be helpful for identifying subgroups of people with schizophrenia at particularly high risk for adverse outcomes. We did not study exposure to antipsychotic medications, as this information was not available for our entire study cohort. This is an important limitation because antipsychotic use, particularly second-generation antipsychotics, are associated with a twofold increased risk of stroke among individuals with 

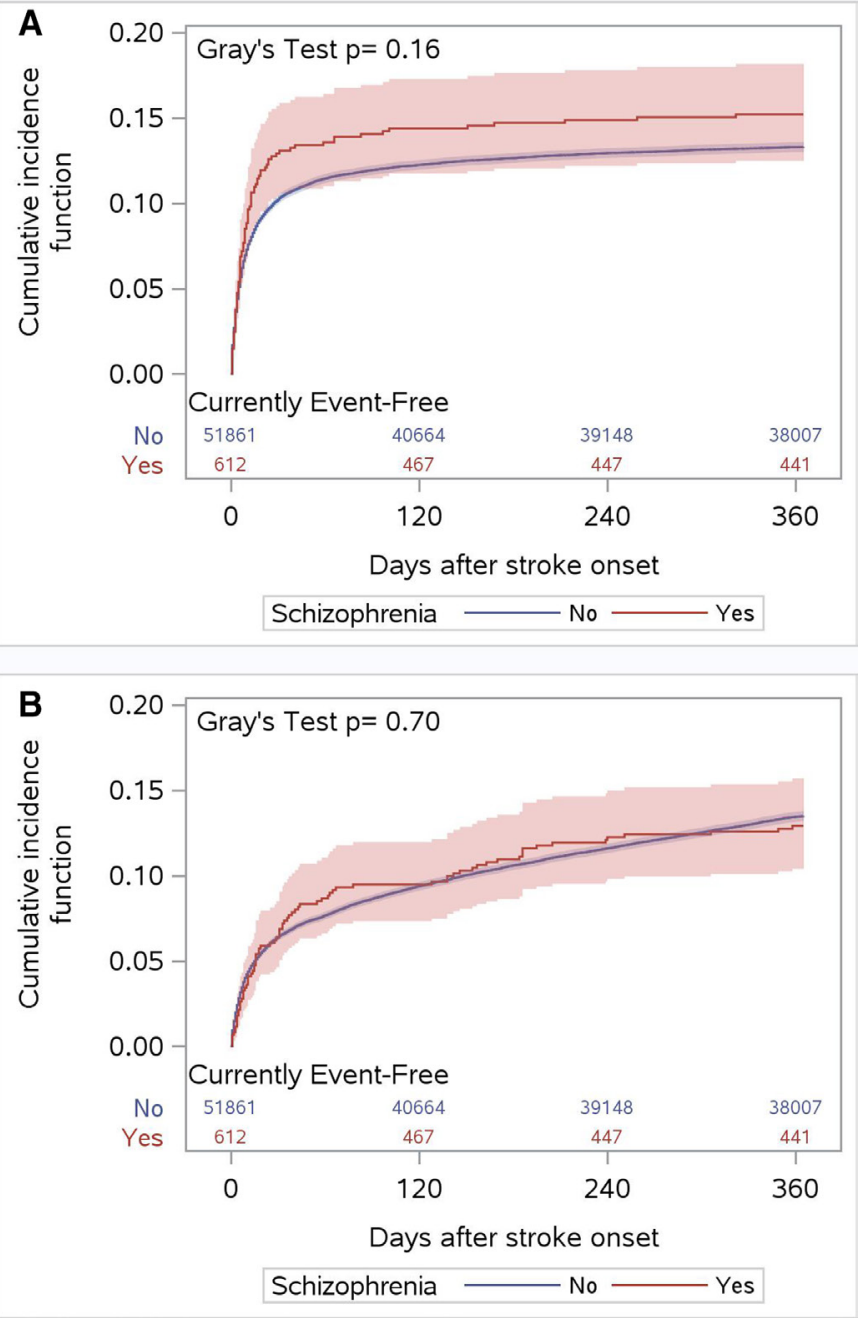

Figure 1 (A) Cumulative incidence of death due to stroke in people with and without schizophrenia. (B) Cumulative incidence of non-stroke death in people with and without schizophrenia.

schizophrenia. ${ }^{9}$ Our data sources did not provide information regarding the severity or control of risk factors such as diabetes or hypertension, on other vascular risk factors such as obesity and physical activity, or on factors such as medication adherence or postdischarge care. We included only people hospitalised with stroke, and thus we do not know if the higher observed stroke severity in people with schizophrenia was due to differences in careseeking behaviour, with people with schizophrenia and minor stroke symptoms less likely to present to hospital than those without schizophrenia. Finally, our study was conducted in a province with universal access to physician and hospital services and may not be generalisable to other settings. Despite these limitations, our large, population-based sample with detailed clinical information and complete follow-up through administrative data is likely to provide valid results on the risks and contributors to death after stroke in people with and without schizophrenia.

In summary, we found that schizophrenia is associated with deficiencies in some aspects of poststroke care, as

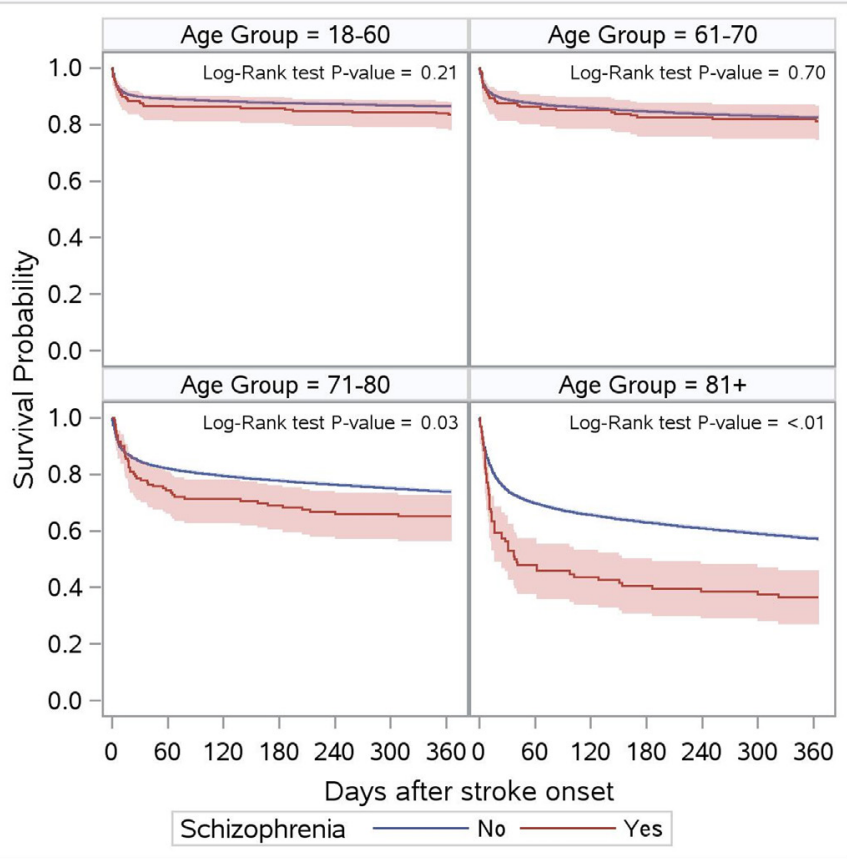

Figure 2 Survival after stroke in people with and without schizophrenia, by age group.

well as a substantial increase in stroke case fatality, which is not fully explained by differences in baseline factors or processes of care. Future work should focus on collaborative efforts among psychiatrists, clinicians with expertise in cardiovascular disease, patients and other stakeholders to understand the reasons for these differences and to develop interventions to improve cardiovascular care and outcomes in people with schizophrenia and other psychotic disorders.

\section{Twitter Moira K Kapral @moirakapral}

Contributors MKK and KAS conceived the study and MKK drafted the manuscript. JF performed the statistical analyses. PK, LKC, JF, JP and KAS contributed to the study design, interpretation of results and revisions to the manuscript.

Funding This study was supported by ICES, which is funded by an annual grant from the Ontario Ministry of Health and Long-Term Care. MKK is supported by a Mid-Career Investigator Award from the Heart and Stroke Foundation of Canada and holds the Lillian Love Chair in Women's Health from the University Health Network/ University of Toronto.

Disclaimer The opinions, results and conclusions reported in this paper are those of the authors and are independent from the funding sources. No endorsement by ICES or the Ontario MOHLTC is intended or should be inferred. Parts of this material are based on data and/or information compiled and provided by the Canadian Institute for Health Information (CIHI). However, the analyses, conclusions, opinions and statements expressed in the material are those of the authors and not necessarily those of $\mathrm{CIHI}$. Parts of this report are based on Ontario Registrar General (ORG) Information on deaths, the original source of which is ServiceOntario. The views expressed therein are those of the authors and do not necessarily reflect those of ORG or Ministry of Government Services.

\section{Competing interests None declared.}

Patient consent for publication Not required.

Ethics approval The use of data was authorised under section 45 of Ontario's Personal Health Information Protection Act, which does not require review by a research ethics board.

Provenance and peer review Not commissioned; externally peer reviewed.

Data availability statement Data are available upon reasonable request. The dataset from this study is held securely in coded form at ICES (formerly known 
as the Institute for Clinical Evaluative Sciences). While data sharing agreements prohibit ICES from making the dataset publicly available, access may be granted to those who meet pre-specified criteria for confidential access, available at http:// www.ices.on.ca/DAS. The full dataset creation plan and underlying analytic code are available from the authors upon request, understanding that the computer programs may rely upon coding templates or macros that are unique to ICES and are therefore either inaccessible or may require modification.

Supplemental material This content has been supplied by the author(s). It has not been vetted by BMJ Publishing Group Limited (BMJ) and may not have been peer-reviewed. Any opinions or recommendations discussed are solely those of the author(s) and are not endorsed by BMJ. BMJ disclaims all liability and responsibility arising from any reliance placed on the content. Where the content includes any translated material, BMJ does not warrant the accuracy and reliability of the translations (including but not limited to local regulations, clinical guidelines, terminology, drug names and drug dosages), and is not responsible for any error and/or omissions arising from translation and adaptation or otherwise.

Open access This is an open access article distributed in accordance with the Creative Commons Attribution Non Commercial (CC BY-NC 4.0) license, which permits others to distribute, remix, adapt, build upon this work non-commercially, and license their derivative works on different terms, provided the original work is properly cited, appropriate credit is given, any changes made indicated, and the use is non-commercial. See: http://creativecommons.org/licenses/by-nc/4.0/.

\section{ORCID iDs}

Moira K Kapral http://orcid.org/0000-0002-3444-9928

Paul Kurdyak http://orcid.org/0000-0001-8115-7437

\section{REFERENCES}

1 Feigin VL, Krishnamurthi RV, Parmar P, et al. Update on the global burden of ischemic and hemorrhagic stroke in 1990-2013: the GBD 2013 study. Neuroepidemiology 2015;45:161-76.

2 Correll CU, Solmi M, Veronese N, et al. Prevalence, incidence and mortality from cardiovascular disease in patients with pooled and specific severe mental illness: a large-scale meta-analysis of $3,211,768$ patients and $113,383,368$ controls. World Psychiatry 2017;16:163-80.

3 Tsai K-Y, Lee C-C, Chou Y-M, et al. The incidence and relative risk of stroke in patients with schizophrenia: a five-year follow-up study. Schizophr Res 2012;138:41-7.

4 Ringen PA, Engh JA, Birkenaes AB, et al. Increased mortality in schizophrenia due to cardiovascular disease - a non-systematic review of epidemiology, possible causes, and interventions. Front Psychiatry 2014;5:137.

5 Bresee LC, Majumdar SR, Patten SB, et al. Prevalence of cardiovascular risk factors and disease in people with schizophrenia: a population-based study. Schizophr Res 2010;117:75-82.

6 Osborn DPJ, Levy G, Nazareth I, et al. Relative risk of cardiovascular and cancer mortality in people with severe mental illness from the United Kingdom's general practice Rsearch database. Arch Gen Psychiatry 2007;64:242-9.

7 Birkenaes AB, Søgaard AJ, Engh JA, et al. Sociodemographic characteristics and cardiovascular risk factors in patients with severe mental disorders compared with the general population. J Clin Psychiatry 2006;67:425-33.

8 Li M, Fan Y-L, Tang Z-Y, et al. Schizophrenia and risk of stroke: a meta-analysis of cohort studies. Int J Cardiol 2014;173:588-90.

9 Chen W-Y, Chen L-Y, Liu H-C, et al. Antipsychotic medications and stroke in schizophrenia: a case-crossover study. PLoS One 2017;12:e0179424

10 Yung NCL, Wong CSM, Chan JKN, et al. Mortality in patients with schizophrenia admitted for incident ischemic stroke: a populationbased cohort study. Eur Neuropsychopharmacol 2020;31:152-7.

11 Kisely S, Campbell LA, Wang Y. Treatment of ischaemic heart disease and stroke in individuals with psychosis under universal healthcare. Br J Psychiatry 2009;195:545-50.

12 Willers C, Sunnerhagen KS, Lekander I, et al. The association of pre-stroke psychosis and post-stroke levels of health, resource utilization, and care process: a register-based study. Front Neurol 2018;9:1042.

13 Kang J-H, Xirasagar S, Lin H-C. Lower mortality among stroke patients with schizophrenia: a nationwide population-based study. Psychosom Med 2011;73:106-11.

14 Prior A, Laursen TM, Larsen KK, et al. Post-stroke mortality, stroke severity, and preadmission antipsychotic medicine use--a population-based cohort study. PLoS One 2014;9:e84103.
15 Kurdyak P, Vigod S, Calzavara A, et al. High mortality and low access to care following incident acute myocardial infarction in individuals with schizophrenia. Schizophr Res 2012;142:52-7.

16 Mohamed MO, Rashid M, Farooq S, et al. Acute myocardial infarction in severe mental illness: prevalence, clinical outcomes, and process of care in U.S. hospitalizations. Can J Cardiol 2019;35:821-30.

17 Bodén R, Molin E, Jernberg T, et al. Higher mortality after myocardial infarction in patients with severe mental illness: a nationwide cohort study. J Intern Med 2015;277:727-36.

18 Kugathasan P, Laursen TM, Grøntved S, et al. Increased long-term mortality after myocardial infarction in patients with schizophrenia. Schizophr Res 2018;199:103-8.

19 Kugathasan P, Horsdal HT, Aagaard J, et al. Association of secondary preventive cardiovascular treatment after myocardial infarction with mortality among patients with schizophrenia. JAMA Psychiatry 2018;75:1234-40.

20 Attar R, Valentin JB, Freeman P, et al. The effect of schizophrenia on major adverse cardiac events, length of hospital stay, and prevalence of somatic comorbidities following acute coronary syndrome. Eur Heart J Qual Care Clin Outcomes 2019;5:121-6.

21 Statistics Canada. Table 051-0001. population by year, by Province and territory, 2019

22 Kapral MK, Hall RE, Stamplecoski M. Registry of the Canadian Stroke Network - Report on the 2008/09 Ontario Stroke Audit. Toronto, ON, 2011.

23 Cadilhac DA, Kim J, Lannin NA, et al. National stroke registries for monitoring and improving the quality of hospital care: a systematic review. Int J Stroke 2016;11:28-40.

24 Kurdyak P, Lin E, Green D, et al. Validation of a population-based algorithm to detect chronic psychotic illness. Can J Psychiatry 2015;60:362-8

25 Kokotailo RA, Hill MD. Coding of stroke and stroke risk factors using International classification of diseases, revisions 9 and 10. Stroke 2005;36:1776-81.

26 Austin PC. Using the standardized difference to compare the prevalence of a binary variable between two groups in observational research. Commun Stat Simul Comput 2009;38:1228-34.

27 Hess KR. Assessing time-by-covariate interactions in proportional hazards regression models using cubic spline functions. Stat Med 1994;13:1045-62.

28 Osborn DPJ, Hardoon S, Omar RZ, et al. Cardiovascular risk prediction models for people with severe mental illness: results from the prediction and management of cardiovascular risk in people with severe mental illnesses (primrose) research program. JAMA Psychiatry 2015;72:143-51.

29 Newcomer JW, Hennekens $\mathrm{CH}$. Severe mental illness and risk of cardiovascular disease. JAMA 2007;298:1794-6.

30 Mangurian C, Newcomer JW, Modlin C, et al. Diabetes and cardiovascular care among people with severe mental illness: a literature review. J Gen Intern Med 2016;31:1083-91.

31 Baller JB, McGinty EE, Azrin ST, et al. Screening for cardiovascular risk factors in adults with serious mental illness: a review of the evidence. BMC Psychiatry 2015;15:55

32 Pitman AL, Osborn DPJ, Wright CA, et al. Cardiovascular screening of people with severe mental illness in England: views of service users and providers. Psychiatr Serv 2011;62:1338-45.

33 Osborn D, Burton A, Hunter R, et al. Clinical and cost-effectiveness of an intervention for reducing cholesterol and cardiovascular risk for people with severe mental illness in English primary care: a cluster randomised controlled trial. Lancet Psychiatry 2018;5:145-54.

34 Osborn DPJ, King MB, Nazareth I. Participation in screening for cardiovascular risk by people with schizophrenia or similar mental illnesses: cross sectional study in general practice. BMJ 2003;326:1122-3.

35 Barker LC, Kurdyak P, Jacob B, et al. Quality of diabetes care for individuals with comorbid chronic psychotic illness: a Sex-Based analysis. J Womens Health 2018;27:290-6.

36 Tsoi DT, Porwal M, Webster AC. Interventions for smoking cessation and reduction in individuals with schizophrenia. Cochrane Database Syst Rev 2013;2:CD007253.

37 Tsai K-Y, Lee C-C, Chou Y-M, et al. The incidence and relative risk of stroke in patients with schizophrenia: a five-year follow-up study Schizophr Res 2012;138:41-7.

38 Reeves M, Khoury J, Alwell K, et al. Distribution of national Institutes of health stroke scale in the Cincinnati/Northern Kentucky stroke study. Stroke 2013;44:3211-3.

39 Smith EE, Fonarow GC, Reeves MJ, et al. Outcomes in mild or rapidly improving stroke not treated with intravenous recombinant tissue-type plasminogen activator: findings from get with the Guidelines-Stroke. Stroke 2011;42:3110-5. 
40 Bongiorno DM, Daumit GL, Gottesman RF, et al. Comorbid psychiatric disease is associated with lower rates of thrombolysis in ischemic stroke. Stroke 2018;49:738-40.

41 Bongiorno DM, Daumit GL, Gottesman RF, et al. Patients with stroke and psychiatric comorbidities have lower carotid revascularization rates. Neurology 2019;92:e2514-21.

42 Lahti M, Tiihonen J, Wildgust $\mathrm{H}$, et al. Cardiovascular morbidity, mortality and pharmacotherapy in patients with schizophrenia. Psychol Med 2012;42:2275-85.
43 Dossa A, Glickman ME, Berlowitz D. Association between mental health conditions and rehospitalization, mortality, and functional outcomes in patients with stroke following inpatient rehabilitation. BMC Health Serv Res 2011;11:311.

44 Druss BG. Can better cardiovascular care close the mortality gap for people with schizophrenia? JAMA Psychiatry 2018;75:1215-6.

45 Wu S-I, Chen S-C, Juang JJM, et al. Diagnostic procedures, revascularization, and inpatient mortality after acute myocardial infarction in patients with schizophrenia and bipolar disorder. Psychosom Med 2013;75:52-9. 